\title{
PERBANDINGAN KUALITAS KRIM ANTARA BASIS ADEPS LANAE DENGAN GHEE ( MENTEGA SUSU SAPI )
}

\author{
A A Mas Siti Sunari ${ }^{1}$ Ni Putu Rahayu Artini ${ }^{2}$ Dewi Puspita Apsari ${ }^{3}$ \\ 1,3Program Studi Farmasi Klinis \\ 2Program Studi Teknologi Laboratorium Medik \\ Universitas Bali Internasional \\ Email :gungmass@yahoo.com
}

\begin{abstract}
Abstrak
Formulasi krim terdapat zat aktif dan basis, basis krim yang paling banyak digunakan ialah adeps lanae(AL)atau lemak bulu domba atau lanolin.Ghee(G) mentega dari susu sapi yang biasa digunakan sebagai bahan masak, ritual dan obat tradisional di India. Karena belum terdapat penelitian tentang ghee sebagai basis krim, sehingga dilakukan penelitian perbandingan kualitas krim antara basis AL dan G. Penelitian ini merupakan jenis eksperimental dengan metode rancangan Rancangan Acak Lengkap. Formulasi krim yang dibuat dengan tipe minyak dalam air (M/A) kemudian dilakukan uji secara fisika dan kimia. Data kualitatif di bandingkan dengan literatur sedangkan data kuantitatif dianalisis independent sample t-test $(\mathrm{p} \leq 0,05)$. Di dapatkan hasil yaitu terdapat perbedaan warna yang dihasilkan, krim AL berwarna putih kekuningan dan krim $\mathrm{G}$ menghasilkan warna putih, viskositas AL lebih tinggi sehingga menghasilkan daya sebar yang rendah; $\mathrm{pH}$ AL lebih basa dibanding $\mathrm{G}$ Uji fisika dan uji kimia nilai sig. $(\mathrm{p} \leq 0,05)$ bermakna terdapat perbedaan signifikan antara basis adeps lanae dengan ghee
\end{abstract}

\section{Kata Kunci: Adeps Lanae, Ghee, Kualitas Krim}

\begin{abstract}
Cream formulations contain active substances and bases, the most widely used cream base is adeps lanae $(A L)$ or fleece fat or lanolin. Ghee $(G)$ butter from cow's milk which is commonly used as a cooking, ritual and medicinal ingredient. traditional in India. Because there has been no research on ghee as a cream base, so a study was conducted. To determine the comparison of the quality of the cream between adeps lanae and ghee bases. Experimental study with a completely randomized design method. Oil-in-water $(O / W)$ cream formulations were made and then tested physical and chemical. The qualitative data were compared with the literature while the quantitative data were analyzed by independent sample $t$-test $(p \leq 0.05)$. the result is There was a difference in color, cream $A L$ was yellowish white and cream $G$ produced white color, the viscosity of $A L$ was higher, resulting in lower dispersibility; $A L \mathrm{pH}$ is more alkaline than $G$; both preparations contained microbial contamination but were still within the range of requirements. Physical test and chemical test of sig. $(p \leq 0.05)$ there is a significant difference between the base of adeps lanae and ghee.
\end{abstract}

Keyword : Adeps Lanae, Ghee, Quality Of Cream 


\section{Pendahuluan}

Dalam formulasi sediaan krim terdapat zat aktif dan basis dimana basis ini merupakan zat pembawa, basis merupakan komponen terbesar pada sediaan semi solid dan merupakan faktor yang harus diperhatikan dalam formulasi suatu sediaan semi solid. Basis produk sediaan semi solid umumnya dikategorikan sesuai jenis sediaan yang akan dibuat. Untuk krim tipe M/A menggunakan adeps lanae atau lemak bulu domba atau lanolin kandungan dari adeps lanae ialah ester-ester lemak dengan kolesterol, setil-alkohol dan karnaubil-alkohol ${ }^{[1]}$. Tipe basis absorbsi seperti Adeps lanae memiliki sifat hidrofilik yaitu memiliki potensi mengabsorbsi air, absopsi air ini hanya menunjukkan pada kemampuan basis didalam menyerap air. Penggunaan adeps lanae kontraindikasi ke pasien yang memiliki hipersensitifitas ke adeps lanae/ lemak bulu domba, efek yang mungkin ditimbulkan ialah kemerahan, rasa terbakar serta penggunaan adeps lanae tidak untuk luka terbuka. Adeps lanae bertendensi menjadi tengik hal ini karena, kandungan adeps lanae yaitu 25-30\% merupakan

\section{Metode}

\section{Rancangan Penelitian}

Penelitian ini merupakan penelitian eksperimental dengan metode Rancangan Acak Lengkap (RAL) yang merupakan suatu rancangan yang digunakan untuk melihat homogen atau tidak adanya faktor lain yang mempengaruhi respon di luar faktor yang diteliti.

\section{Alat dan bahan}

Alat yang digunakan dalam penelitian ini Alat untuk pembuatan krim, yaitu Mikro pipet, penangas air, gelas ukur (Pyrex) $50 \mathrm{ml}$, Erlenmeyer (Pyrex) $100 \mathrm{ml}, 250 \mathrm{ml}$, pinset, pisau, sendok tanduk, termometer, wadah krim, mortir dan stamper dan penangas air. Alat untuk evaluasi sediaan krim adalah timbangan analitik, kertas perkamen, kertas saring, kaca, cawan porselen, beker glass, labu tentukur $100 \mathrm{ml}$, pipet tetes, elenmeyer, batang pengaduk, gelas ukur, pipet ukur $10 \mathrm{ml}, 1 \mathrm{ml}, 2 \mathrm{ml}, 5 \mathrm{ml}$, dan $20 \mathrm{ml}$, aluminium foil, sendok tanduk, spatel, pipet tetes, air, selain itu industrial kosmetika sangat jarang menggunakan adep lanae sebagai basis produk ${ }^{[2]}$. Untuk itu peneliti memilih menggunakan ghee yang merupakan jenis mentega yang diproduksi dari susu sapi yang biasa digunakan untuk memasak serta ritual di India. Kandungan dari gheevitamin A 2849 IU, vitamin K $9.98 \mu \mathrm{g}$, karoten $181 \mu \mathrm{g}$, tokoferol $2.61 \mathrm{mg}$, kalsium 7.25 mg dan kalium $7.25 \mathrm{mg}{ }^{[3]}$.

Hal yang mendasari pemilihan ghee sebagai basis krim ialah ghee dapat digunakan untuk luka terbuka serta memiliki daya simpan yang jauh lebih lama daripada adeps lanae, hal ini tentunya dapat meningkatkan value suatu krim jika menggunakan ghee sebagai basis produk.

Tujuan dari penelitian ini untuk mengetahui perbandingan kualitas krim antara basis adeps lanae dengan ghee (mentega dari susu sapi) yang disesuaikan dengan standar BPOM terkait obat tradisional dan beberapa tambahan literatur lain. Manfaat penelitian yaitu dapat mengembangkan potensi dari ghee sehingga dapat menghasilkan produk yang bila dikembangkan efektifitasnya dapat dirasakan oleh masyarakat luas.

autoklaf, kertas $\mathrm{pH}$, ph meter kertas perkamen, kertas saring, oven, viskometer (Brookfield), pipet volume, colony counter (alat hitung koloni), cawan petri, Bunsen dan vortex. Bahan untuk pembuatan krim adalah asam stearat, ghee, adeps lanae, akuadest, gliserin, trietanolamin ,metil paraben, dan propil paraben dan alkohol $70 \%$.

\section{Prosedur penelitian}

\section{Pembuatan sediaan krim}

Alat dan bahan yang akan digunakan disiapkan yang meliputi fase minyak dibuat dengan melebur asam stearate, ghee, adeps lanae diatas kompor listrik dengan suhu $65-70^{\circ} \mathrm{C}$. Fase air dibuat dengan melarutkan metil paraben, propil paraben, TEA, gliserin dan akuadest dipanaskan diatas kompor listrik dengan suhu $65-70^{\circ} \mathrm{C}$. Kemudian fase minyak dituangkan ke wadah dan ditambahkan sedikit demi sedikit kedalam fase air lalumixer selama 3 menit, sampai terbentuk krim yang homogen. Formulasi krim diambil dari penelitian yang telah dilakukan oleh (Purwaningrum, 2016). 
Tabel 1. Formulasi Krim Basis Adeps Lanae

\begin{tabular}{ccc}
\hline Fase M/A & Bahan & Formulasi \\
\hline Minyak & Asam stearat & $15 \%$ \\
Minyak & Adeps lanae & $5 \%$ \\
Air & Gliserin & $10 \%$ \\
Air & Trietanolamin & $3 \%$ \\
Air & Metil paraben & $0,18 \%$ \\
Air & Propil paraben & $0,02 \%$ \\
Air & Akuadest & $\mathrm{ad} 100 \%$ \\
\hline
\end{tabular}

Tabel 2.Formulasi Krim Basis Ghee

\begin{tabular}{ccc}
\hline Fase M/A & Bahan & Formulasi \\
\hline Minyak & Asam stearat & $15 \%$ \\
Minyak & Ghee & $5 \%$ \\
Air & Gliserin & $10 \%$ \\
Air & Trietanolamin & $3 \%$ \\
Air & Metil paraben & $0,18 \%$ \\
Air & Propil paraben & $0,02 \%$ \\
Air & Akuadest & ad 100\% \\
\hline
\end{tabular}

\section{Evaluasi fisika dan kimia krim}

Pengujian sifat fisika krim basis adeps lanae maupun ghee meliputi pemeriksaan organoleptik yaitu warna, bau, tekstur, homogenitas, viskositas dengan viskometer Bookfield nomor spindel 64 dan daya sebar dengan beban $50 \mathrm{~g} ; 100 \mathrm{~g} ; 150 \mathrm{~g}$. Analisis kimia meliputi pemeriksaan $\mathrm{pH}$, dengan $\mathrm{pH}$ meter.

\section{Analisis data}

Data yang diperoleh berupa data kualitatif dan kuantitatif. Pada data kualitatif diperoleh dari pengamatan homogenitas, organoleptik, identifikasi Stapylococcous aureus, identifikasi Pseudomonas aeruginosa. Data kuantitatif diperoleh dari uji viskositas, uji daya sebar, uji ph, uji ALT dan uji AKK.

Data kualitatif analisis dilakukan dengan membandingkan hasil dengan literatur terkait. Datakuantitatif dilakukan uji analisis menggunakan SPSS (Statistikal Package for the Social Sciences) yaitu data yang diperoleh kemudian dianalisa dengan uji normalitas Kolmogorov smirnov menghasilkan nilai signifikansi $(\mathrm{p} \geq 0,05)$. Selanjutnya dilakukan uji homogenitas dengan Levene test dengan nilai ( $\mathrm{p}$ $\geq 0,05$ ) dan untuk penentuan nilai mean atau rerata dari dua sample dengan independent sample $t$ test dengan nilai signifikansi $(\mathrm{p} \leq 0,05)$.

\section{Hasil Dan Pembahasan}

Adapun hasil dari formulasi krim basis adeps lanae dan ghee serta uji fisika, kimia dan mikrobiologi

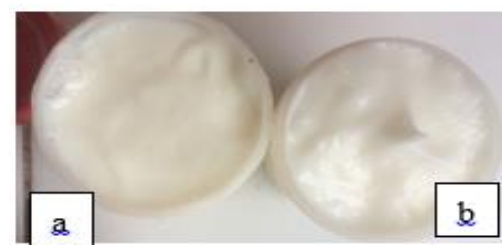

Gambar 1. Hasil formulasi krim

Pada gambar 1 menunjukan a merupakan krim basis adeps lanae dan $b$ merupakan krim basis ghee. 
Tabel 3. Hasil uji sifat fisika dan kimia krim basis adeps lanae (BA) dank rim krim basis ghee.

\begin{tabular}{|c|c|c|c|c|}
\hline Uji Fisika & Syarat & BA & BG & Signifikansi \\
\hline \multirow{3}{*}{ Organoleptik } & $\begin{array}{c}\text { Warna : tidak } \\
\text { mencolok }\end{array}$ & $\begin{array}{l}\text { Warna : putih } \\
\text { kekuningan }\end{array}$ & Warna : putih & - \\
\hline & $\begin{array}{l}\text { Tekstur: } \\
\text { lembut }\end{array}$ & Tekstur:lembut & Tekstur:lembut & - \\
\hline & $\begin{array}{l}\text { Bau : tidak } \\
\text { menyengat }\end{array}$ & Bau : khas & Bau : khas & - \\
\hline Homogenitas & Homogen & Homogen & Homogen & - \\
\hline \multicolumn{5}{|l|}{$\begin{array}{l}\text { Viskositas } \\
\text { (cps) }\end{array}$} \\
\hline \multicolumn{5}{|l|}{$\begin{array}{c}\text { Daya sebar }(\mathrm{cm}) \\
50 \mathrm{~g}\end{array}$} \\
\hline$\frac{100 \mathrm{~g}}{150 \mathrm{~g}}$ & $5-7$ & $\begin{array}{l}5,18 \pm 0,16 \\
5,42 \pm 0,10 \\
5,50 \pm 0,10\end{array}$ & $\begin{array}{l}5,33 \pm 0,20 \\
5,47 \pm 0,18 \\
5,63 \pm 0,18\end{array}$ & 0,016 \\
\hline Uji Kimia & Syarat & $\mathbf{B A}$ & BG & Signifikansi \\
\hline $\mathrm{Ph}$ & $5-8$ & $7,5 \pm 0,1$ & $6,5 \pm 0,15$ & 0.001 \\
\hline
\end{tabular}

\section{Uji organoleptik}

Hasil uji organoleptik diperoleh, krimdengan basis adeps lanae berwarna putih kekuningan sedangkan krim basis ghee berwarna putih, dan kedua krim memiliki tekstur lembut dan aroma khas. Perbedaan warna yang dihasilkan karena, adeps lanae berwarna kuning dan bertekstur lemak yang pekat sehingga menghasilkan warna krim yang putih kekuningan, sedangkan krim basis ghee berwarna putih hal ini karena ghee berasal dari susu sapi ${ }^{[5]}$.

\section{Uji homogenitas}

Bertujuan untuk mengetahui tercampurnya fase minyak dan fase air krim sehingga dapat memebentuk massa krim secara sempurna, pada penelitian ini kedua krim yang dihasilkan sudah tercampur secara merata dan tidak terdapat partikel kasar, hal ini bermakna fase minyak dan fase air krim sudah tercampur secara sempurna dan kedua sediaan krim dinyatakan homogen karena memiliki tekstur yang tampak rata dan tidak ada bagian yang menggumpal ${ }^{[6]}$.

\section{Uji viskositas}

Pada pengujian viskositas nilai yang diperoleh krim basis adeps lanae $18.200 \mathrm{cps}$ dan krim basis ghee $16.453 \mathrm{cps}$. Data tersebut diuji secara statistik dengan independent sample t-test dan di dapatkan nilai signifikansi $\quad 0,000 \quad(\mathrm{p} \leq 0,05), \quad$ bermakna antarakrim basis adeps lanae dan ghee terdapat perbedaan signifikan. Perbedaan nilai viskositas yang diperoleh karena konsistensi dari bahan basis yang digunakan dimana, adeps lanae memiliki tekstur liat, kental serta padat ${ }^{[10]}$ sedangkan ghee memiliki tekstur lembek dan mudah meleleh pada suhu ruang ${ }^{[11]}$. membuat krim basis dari adeps lanae lebih kental dibanding dengan ghee. Nilai viskositas ini akan berdampak ke daya sebar dari krim.

\section{Uji daya sebar}

Bertujuan untuk menggambarkan kemudahan krim ketika diaplikasikan pada kulit. Suatu sediaan akan disukai bila dapat menyebar dengan mudah serta merata di kulit, sehingga lebih nyaman. Krim basis adeps lanae memiliki rentang daya sebar 5,18-5,50 cm sedangkan krim basis ghee $5,33-5,63 \mathrm{~cm}$. Untuk mengetahui perbedaan signifikan data dilakukan uji statistik dengan independent sample t-tets diperoleh nilai $0,016 \quad(\mathrm{p} \leq 0,05) \quad$ bermakna terdapat perbedaan signifikan daya sebar kedua sediaan krim.Sediaan yang memiliki viskositas lebih rendah atau lebih encer dalam penelitian ini dihasilkan oleh krim basis ghee, yang menghasilkan diameter penyebaran yang lebih besar karena lebih mudah untuk mengalir. viskositas yang lebih rendah, maka diameter penyebarannya semakin luas ${ }^{[12]}$. 


\section{Uji kimia}

Pengujian kimia pada sediaan krim yaitu dengan mengukur kadar $\mathrm{pH}$ dari krim. Tujuan dilakukannya uji pH karena suatu sediaan semi solida dengan $\mathrm{pH}$ yang terlalu asam $\leq 4$ bersifat iritatif pada kulit dan $\mathrm{pH}$ sediaan terlalu basa $\geq 10$ menyebabkan kulit menjadi gatal dan bersisik ${ }^{[9]}$. Hasil yang didapat untuk krim basis adeps lanae 7,5 dan krim basis ghee 6,5, Untuk mengetahui perbedaan kualitas krim secara statistik dilakukan uji independent sample t-test dan diperoleh hasil $0,001(\mathrm{p} \leq 0,05)$ menunjukan terdapat perbedaan signifikan antara basis adeps lanae dan ghee Perbedaan signifikan antara basis adeps lanae dan ghee. Krim basis yang mengandung adeps lanae memiliki ph lebih basa, dikarenakan adeps lanae memiliki kandungan ester asam lemak yang membuat sediaan yang dihasilkan memiliki ph diatas 7 , sedangkan pada ghee terdapatnya kandungan tokoferol sehingga $\mathrm{pH}$ yang dihasilkan sesuai dengan $\mathrm{pH}$ kulit ${ }^{[3]}$.

\section{Simpulan Dan Saran}

\section{Simpulan}

Dari hasil dan pembahasan penelitian yang telah dilakukan diperoleh simpulan, terdapat perbedaan kualitas krim antara basis adeps lanae maupun ghee pada uji organoleptik dimana, krim basis adeps lanae menghasilkan warna putih kekuningan sedangkan krim basis ghee menghasilkan warna putih. Pada uji fisika yaitu viskositas nilai sig. $0,000(\mathrm{p} \leq 0,005)$; daya sebar $0,016(\mathrm{p} \leq 0,005)$ dan uji kimia yaitu $\mathrm{pH}$ nilai sig. $0,001(\mathrm{p} \leq 0,005)$ terdapat perbedaan signifikan antara krim basis adeps lanae maupun ghee.

\section{Saran}

Saran yang bisa disampaikan pada penelitian berikutnya adalah : perlu dilakukannya penelitian lebih lanjut terkait krim basis ghee serta konsentrasi yang baik yang dapat digunakan dan perlu dilakukan penelitian lebih lanjut untuk mengetahui potensi dari ghee untuk menyembuhkan luka.

\section{Daftar Rujukan}

1. Willey Jhon. Pharmaceutical Manufacturing Handbook: Production and Processes. California : Willey-Interscience;2008.

2. Mueler, Ralf S. Topical dermatological therapy : in Small Animal Clinical Pharmacology (Second Edition);2008.

3. Kwak, Hae Soo et al. Butter, Ghee, and Cream Products. Korea.: Universitas Sejong; 2017.

4. BPOM. Metode Analisis PPOMN. MA PPOMN nomor 96/mik/00;2006.

5. BPOM. Peraturan Kepala Badan Pengawas Obat Dan Makanan Republik Indonesia Nomor 12 Tahun 2014 Tentang Persyaratan Mutu Obat Tradisional ; 2014.p. 18.

6. Swastika, A, Mufrod \& Purwanto. Aktivitas Antioksidan Krim Ekstrak Sari Tomat (Solanum lycopersicum L.)[jurnal] ,Trad Med Journal; 2013.

7. Fuuta, S.Formulasi Lotion dan Penentuan Nilai Sun Proctection Factor (SPF) Ekstrak Kulit Buah Naga Super Merah (Hylocereus costaricensis). KTI. Kendari: Akademi Farmasi Bina Husada Kendari;2016.

8. Rachmalia N., Mukhlishah I., Sugihartini N., Yuwono T. "Daya iritasi dan sifat fisik sediaan salep minyak atsiri bunga cengkih (Syzigium aromaticum) pada basis hidrokarbo". (jurnal);2016.

9. Saryanti et al. Optimasi Formula Sediaan Krim M/A Dari Ekstrak Kulit Pisang Kepok (Musa acuminata L.). Surakarta : Sekolah Tinggi Ilmu Kesehatan Nasional; 2019. (vol 1 No.3).

10. Abate, M. and Abel, S. K. Remington: The Science and Practice of Pharmacy 21st Edition, Lippincott Williams and Wilkins, 772, University of The Sciences, Philadelphia,Abate; 2006.

11. Udwadia. Ghee and honey for infected wound. India : Hinduja Nasional Hospital; 2011.

12. Husnani,Moh Firdaus.Optimasi Parameter Fisik Viskositas, Daya Sebar Dan Daya Lekat Pada Basis Natrium Cmc Dan Carbopol 940 Pada Gel Madu Dengan Metode Simplex Lattice Design.[Jurnal] Pontianak : Akademi Farmasi Pontianak; 2013 (No. 6651).

13. Santika. Panduan Pratikum Mikrobiologi. Yogyakarta : Universitas Sanata Dharma; 2016.

14. Todar, K. Regulation and Control of Metabolism in Bacteria.Wisconsin : University of Wisconsin;2012. 
15. Entjang, I. Mikrobiologi dan Parasitologi untuk Akademi Keperawatan dan Sekolah Tenaga Kesehatan yang Sederajat: PT. Citra Aditya Bakti, Jakarta; 2003.
16. Liofilchem.Buffered Peptone Water Diluent and non-selective pre-enrichment liquid medium for microbiological. France : Laboratorie humeau; 2014. 